Check for updates

Cite this: RSC Adv., 2021, 11, 39718

Received 27th September 2021

Accepted 2nd December 2021

DOI: $10.1039 / \mathrm{d} 1 \mathrm{ra0} 07213 \mathrm{~g}$

rsc.li/rsc-advances

\section{Bis-cyclometalated iridium(III) complexes with terpyridine analogues: syntheses, structures, spectroscopy and computational studies $\dagger$}

\author{
Haleema Y. Otaif, ${ }^{a}$ Samuel J. Adams, ${ }^{a}$ Peter N. Horton, ${ }^{b}$ Simon J. Coles, (D) ${ }^{b}$ \\ Joseph M. Beames ${ }^{* a}$ and Simon J. A. Pope (D)*a
}

\begin{abstract}
Two ligands based upon a 2,6-disubstituted pyridine bridge introduce bis-quinoxalinyl units in a fashion that yields analogues to the archetypal terdentate ligand, $2,2^{\prime}: 6^{\prime}, 2^{\prime \prime}$-terpyridine. The ligands were synthesised from the key intermediate 2,6-bis(bromoacetyl)pyridine: a new, high-yielding route is described for this reagent. Two ligand variants (differentiated by $\mathrm{H} / \mathrm{Me}$ substituents on the quinoxaline ring) were explored as coordinating moieties for iridium(III) in the development of luminescent complexes. Computational studies (DFT approaches employing B3LYP, B3LYP/LANL2DZ, and M062X/LANL2DZ levels) were used to investigate the geometric and coordination mode preferences of the new ligands and two possibilities arose from theoretical investigations: $\left[\operatorname{lr}\left(\mathrm{N}^{\wedge} \mathrm{N}^{\wedge} \mathrm{N}\right)_{2}\right]^{3+}$ and $\left[\operatorname{lr}\left(\mathrm{N}^{\wedge} \mathrm{N}^{\wedge} \mathrm{C}\right)_{2}\right]^{+}$, with the former predicted to be more energetically favourable. Upon synthesis and isolation of the $\operatorname{Ir}(\mathrm{III})$ complexes, X-ray crystallographic studies revealed coordination spheres that were cyclometalated, the structures both showing a $\left[\operatorname{Ir}\left(\mathrm{N}^{\wedge} \mathrm{N}^{\wedge} \mathrm{C}\right)_{2}\right] P F_{6}$ arrangement. Further spectroscopic characterization via NMR confirmed the ligand arrangements in the complexes, and photophysical studies, supported by DFT, showed that a mixture of metal-to-ligand charge transfer (MLCT) and intra-ligand charge transfer (ILCT) character is likely to contribute to the emission features of the complexes, which phosphoresce orange-red $\left(\lambda_{\mathrm{em}}=580-618\right.$ $\mathrm{nm})$. The emission wavelength was influenced by the substituents on the quinoxaline ring ( $\mathrm{H} v \mathrm{~s}$. Me), thereby implying further tuneability is possible with future ligand iterations.
\end{abstract}

\section{Introduction}

Luminescent coordination compounds based upon organometallic iridium(III) species have attracted significant attention over the last 25 years. ${ }^{1}$ Interest and continued developments have been driven by the important applications of such compounds. Areas such as photoredox catalysis, ${ }^{2}$ light emitting diodes, ${ }^{3}$ electroluminescent devices ${ }^{4}$ and bioimaging applications ${ }^{5}$ have all continued to benefit from the use of luminescent cyclometalated Ir(III) complexes. Since the electronic properties of such complexes can be tuned using the coordinating ligands, continued efforts are focused upon new chelating agents that can impart useful physical properties upon the complex. ${ }^{6}$ Homoleptic $\left[\operatorname{Ir}(\mathrm{ppy})_{3}\right]$ (where ppy $=$ 2-phenylpyridine) or cationic $\left[\operatorname{Ir}(\mathrm{ppy})_{2}(\mathrm{~L})\right]^{+}$complexes are the archetypal luminescent

${ }^{a}$ School of Chemistry, Main Building, Cardiff University, Cardiff CF10 3AT, UK. E-mail: popesj@cardiff.ac.uk

${ }^{b}$ UK National Crystallographic Service, Chemistry, Faculty of Natural and Environmental Sciences, University of Southampton, Highfield, Southampton, SO17 1BJ, England

$\dagger$ Electronic supplementary information (ESI) available. CCDC 2101342 and 2101343. For ESI and crystallographic data in CIF or other electronic format see DOI: $10.1039 / \mathrm{d} 1 \mathrm{ra} 07213 \mathrm{~g}$
Ir(III) species where the ppy ligand cyclometalates in a bidentate $\mathrm{C}^{\wedge} \mathrm{N}$ fashion. In fact many ligands developed for cyclometalation with $\operatorname{Ir}\left(\right.$ III) are often variants on the ppy structure ${ }^{7}$ and thus intrinsically bidentate in nature. In contrast, luminescent $\operatorname{Ir}(\mathrm{III})$ complexes incorporating terdentate ligands are less common, despite initial reports of such systems $>25$ years ago.

Firstly, $\left[\operatorname{Ir}(\text { terpy })_{2}\right]^{3+}$ (where terpy $=2,2^{\prime}: 6^{\prime}, 2^{\prime \prime}$-terpyridine) is a well-known compound that possesses a $\mathrm{N}^{\wedge} \mathrm{N}^{\wedge} \mathrm{N}$ binding mode, and shows a structured emission band in the blue-green region attributed to ligand-centred triplet states $^{8}$ (and thus contrasts with the typical ${ }^{3}$ MLCT $/{ }^{3}$ LLCT emission character of $\left[\operatorname{Ir}(\text { ppy })_{3}\right]$ and $\left.\left[\operatorname{Ir}(\text { ppy })_{2}(\text { bipy })\right]^{+}\right)$. Heteroleptic luminescent $\operatorname{Ir}(\mathrm{III})$ complexes that incorporate terpy have also been reported to possess ligand tuneable emission characteristics. ${ }^{9}$ Also of direct relevance is the prior work of Campagna (Scheme 1) on the complexation of 2,6-bis(7'-methyl-4'-phenyl-2'-quinolyl)pyridine ${ }^{10}$ where it was shown that the ligand cyclometalates with $\operatorname{Ir}\left(\right.$ III) to give both $\left[\operatorname{Ir}\left(\mathrm{N}^{\wedge} \mathrm{N}^{\wedge} \mathrm{C}\right)_{2}\right]^{+}$and $\left[\operatorname{Ir}\left(\mathrm{N}^{\wedge} \mathrm{N}^{\wedge} \mathrm{N}\right)\left(\mathrm{N}^{\wedge} \mathrm{N}^{\wedge} \mathrm{C}\right)\right]^{2+}$ luminescent species. ${ }^{11}$

Several groups ${ }^{12-14}$ have also reported a number of important $\operatorname{Ir}($ III) complexes that incorporate structural analogues of terpy, including $\mathrm{N}^{\wedge} \mathrm{N}^{\wedge} \mathrm{C}$ (via phenyl-2,2'-bipyridine derivatives), $\mathrm{N}^{\wedge} \mathrm{C}^{\wedge} \mathrm{N}$ (via dipyridyl-benzene derivatives) and $\mathrm{C}^{\wedge} \mathrm{N}^{\wedge} \mathrm{C}$ (via $2,6-$ 


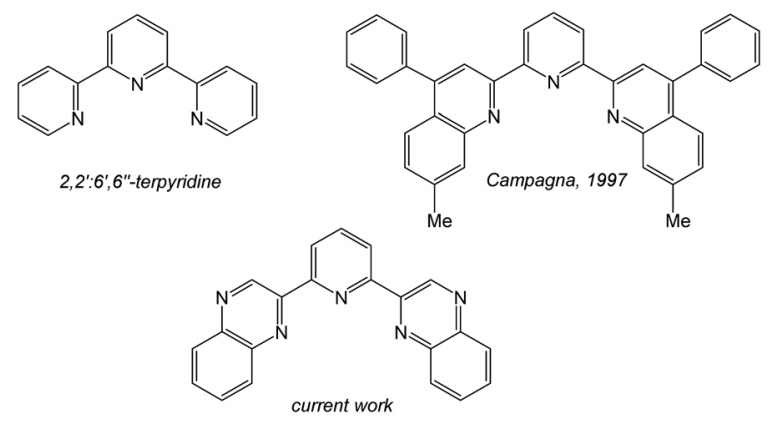

Scheme 1 A comparison of terdentate ligand structures directly relevant to this work.

diphenylpyridine) coordination modes at Ir(III). The design principles and applications of emissive bis-terdentate $\operatorname{Ir}(\mathrm{III})$ complexes have been reviewed ${ }^{15}$ highlighting particularly attractive assemblies for photoactive multi-metallic constructs; terdentate ligands allow the design of linear (or pseudo axial symmetry) and rigid assemblies which are advantageous when studying intramolecular electron or charge transfer phenomena ${ }^{16}$ (commonly mixed ligand formulations support the design of such systems ${ }^{17}$ ). Terdentate ligands can also be deployed as bridging moieties in dinuclear $\operatorname{Ir}(\mathrm{III})$ complexes, which have shown impressive emission properties, ${ }^{18}$ and have been reported as emissive components of polymers. ${ }^{19}$ However, among these reports there are clearly inherent challenges reported with the purification of the target complexes because of the kinetic inertness of $\operatorname{Ir}(\mathrm{III})$ and the different isomeric forms that often arise from terdentate ligand systems. ${ }^{15}$

Inspired by these earlier studies, and as part of our ongoing investigations into quinoxaline-based ligand systems for $\operatorname{Ir}(\mathrm{III}){ }^{20}$ this current work describes the successful synthesis of the first 2,6-bis-quinoxalinyl pyridine analogues of terpyridine. This new ligand architecture provides an extended $\pi$-conjugation to the ligand framework and can be synthesised in a manner that advantageously allows a degree of functionalisation at the quinoxaline moiety. Therefore the aim of the current study was to structurally clarify the coordination chemistry preferences (Scheme 2) of the new ligands with $\operatorname{Ir}(\mathrm{III})$, and reveal their resultant spectroscopic properties, including photophysical attributes.

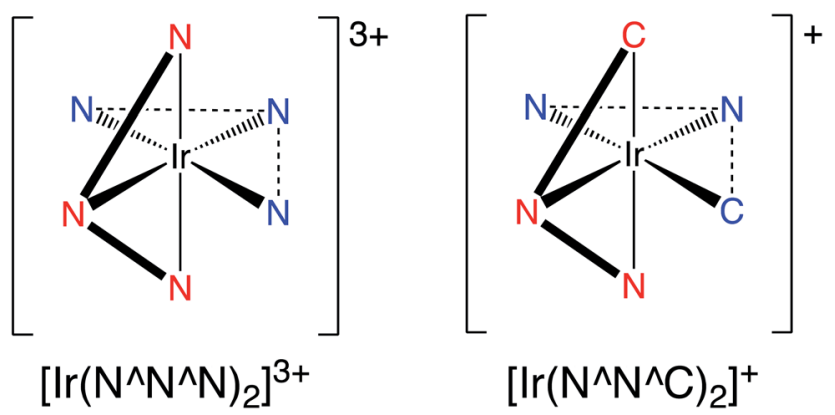

Scheme 2 A comparison of the two coordination modes under consideration in a bis-terdentate coordination sphere at $\operatorname{Ir}(\mathrm{III})$.

\section{Results and discussion}

\section{Ligand design and synthesis}

The ligands were synthesised (Scheme 3) in two steps from commercially available 2,6-diacetylpyridine. Despite its obvious potential in ligand development, 2,6-bis(bromoacetyl)pyridine has only been reported a handful of times ${ }^{21}$ and the bromination routes from the diacetyl precursor typically use either $\mathrm{N}$ bromosuccinimide, $\mathrm{HBr}$ and/or $\mathrm{Br}_{2}$. However, over-bromination is common with these reagents and thus purification can be tedious and limiting to overall yields; the mixture of compounds from the bromination of a diacetyl presumably explains the relatively poor yields previously reported for this compound. As an alternative, we investigated the use of dioxane-dibromide $^{22}$ as an easily handled, solid form of brominating agent. Heating 2,6-diacetylpyridine in 1,4-dioxane with dioxane-dibromide over $3 \mathrm{~h}$ led to the formation of 2,6bis(bromoacetyl)pyridine, which could be obtained in multigram (>10 g) scale, in good yield (67\%), and without need for further purification. As indicated by ${ }^{1} \mathrm{H}$ NMR analyses, these conditions retard unwanted over-bromination that is commonly associated with other reagents and is thus free of time-consuming purification procedures which can compromise yields. 2,6-Bis(bromoacetyl)pyridine was then reacted with either 1,2-phenylenediamine or 4,5-dimethyl-1,2phenylenediamine to give the corresponding bis-quinoxalinyl pyridine derivatives dqxp1 and dqxp2, respectively.

Purification of the ligands by column chromatography returned moderate yields, with the products characterized by ${ }^{1} \mathrm{H}$ and ${ }^{13} \mathrm{C}$ NMR spectroscopy and high resolution mass spectrometry (HRMS). NMR studies of the ligands showed resonances in concordance with a plane of symmetry through the central pyridyl ring, evidenced by a triplet peak at $c a .8 \mathrm{ppm}$ for the proton at the 4-position of the pyridine, as well as a doublet with an integral of $2 \mathrm{H}$ at $8.60 \mathrm{ppm}$. A singlet proton resonance was observed $c a .10 \mathrm{ppm}$ consistent with the formation of the quinoxaline heterocyclic moiety.

Reaction of the ligands with hydrated $\mathrm{IrCl}_{3}$ initially gave the putative intermediate ' $\left\{\mathrm{IrCl}_{3}(\mathbf{d q x p})\right\}$ ', which is likely to be a dimeric species, $[\operatorname{IrCl}(\mathbf{d q x p})]_{2}-\mu-\mathrm{Cl}_{2}$, as reported by Williams ${ }^{\mathbf{1 3}}$ in previous studies on different terdentate cyclometalating ligands. These intermediate species possessed very limited solubility preventing any meaningful characterisation via NMR spectroscopy. The crude intermediate was therefore reacted with another equivalent of the ligand in refluxing ethylene

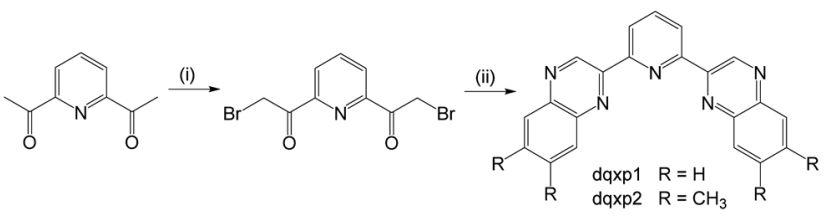

Scheme 3 Synthetic pathway to the target ligands. Reagents and conditions: (i) excess 1,4-dioxane dibromide, dioxane, heat, 3 h; (ii) 2 eq. of 1,2-phenylenediamine or 4,5-dimethyl-1,2-phenylenediamine, 1,4-dioxane, heat, $16 \mathrm{~h}$. 
glycol. Precipitation of the crude complexes was achieved as their hexafluorophosphate salts. These materials were then subjected to column chromatography (silica gel; DCM/MeOH solvent gradient), where a number of coloured bands were observed. The dominant orange-red band was collected and drying in vacuo afforded the purified species in modest yields.

\section{Structural characterisation of the complexes: X-ray crystallography studies}

Single crystals suitable for diffraction studies were obtained for both complexes using vapour diffusion of diethyl ether into concentrated acetonitrile solutions. Full data collection parameters are provided in the ESI (Table S1 $\dagger$ ). The structural analyses show the complexes to be $\left[\operatorname{Ir}\left(\mathbf{d q x p 1 ^ { - }}\right)_{2}\right] \mathrm{PF}_{6}$ (red prism like crystals) and $\left[\operatorname{Ir}\left(\mathbf{d q x p} 2^{-}\right)_{2}\right] \mathrm{PF}_{6}$ (red plate-shaped crystals). The structures unequivocally reveal that both ligands adopt a $\mathrm{N}^{\wedge} \mathrm{N}^{\wedge} \mathrm{C}$ coordination mode and are anionic and cyclometalated. The metalated carbon is thus adjacent to the nitrogen of one of the quinoxaline rings. This coordination mode imparts a distorted octahedral coordination geometry at Ir(III). The complex unit is therefore mono-cationic and charge balanced by one hexafluorophosphate counter anion.

Table 1 shows the bond lengths describing the coordination sphere of the complexes. In both structures the mutually trans Ir- $\mathrm{N}_{\mathrm{py}}$ bond lengths are slightly shorter than the $\mathrm{Ir}-\mathrm{N}_{\mathrm{qx}}$ bonds. The structure for $\left[\operatorname{Ir}(\text { terpy })_{2}\right]\left(\mathrm{PF}_{6}\right)_{3}$ describes ${ }^{23} \mathrm{Ir}-\mathrm{N}$ bonds in the range 1.978-2.058 $\AA$ and is therefore comparable to the majority of the Ir-N distances reported here. It is evident that both Ir-N and $\mathrm{Ir}-\mathrm{C}$ bond lengths compare closely to monocationic complexes that feature cyclometalated 2-phenylquinoxaline ligands. ${ }^{20}$ Examination of the bite angles within each coordinated terdentate ligand shows that the three trans angles are again comparable to other structures incorporating terpy ligands. ${ }^{24}$ In the two complexes described here, the N-Ir-N trans angles are approximately $5^{\circ}$ less than the $\mathrm{C}-\mathrm{Ir}-\mathrm{N}$ angles (Table $\left.\mathrm{S} 2, \mathrm{ESI}^{\dagger}\right)$. We note that the trans $\mathrm{N}-\mathrm{Ir}-\mathrm{N}$ bond angle is closer to $180^{\circ}$ in the methylated complex, $\left[\operatorname{Ir}\left(\mathbf{d q x p 2}^{-}\right)_{2}\right] \mathrm{PF}_{6}$.

The packing diagrams for both species are included in the ESI (Fig. S2 and S3 $\dagger$ ) and reveal long-range ordering induced by intermolecular interactions supported by $\pi$-stacking of the aromatic ligand constituents. Interestingly, for $\left[\operatorname{Ir}\left(\mathbf{d q x p} \mathbf{1}^{-}\right)_{2}\right] \mathrm{PF}_{6}$ it is the $\mathrm{N}$-coordinated quinoxaline rings that stack (at $3.562 \AA$ ),

Table 1 Experimental bond lengths obtained from the X-ray crystal structures

\begin{tabular}{|c|c|c|c|c|c|}
\hline \multicolumn{3}{|c|}{$\left[\operatorname{Ir}\left(\mathbf{d q x p 1}^{-}\right)_{2}\right] \mathrm{PF}_{6}$} & \multicolumn{3}{|c|}{$\left[\operatorname{Ir}\left(\mathbf{d q x p 2}^{-}\right)_{2}\right] \mathrm{PF}_{6}$} \\
\hline Atom & Atom & Length/Å & Atom & Atom & Length/Å \\
\hline $\operatorname{Ir}(1)$ & $\mathrm{N}(1)$ & $1.999(2)$ & $\operatorname{Ir}(1)$ & $\mathrm{N}(1)$ & $2.009(5)$ \\
\hline $\operatorname{Ir}(1)$ & $\mathrm{N}(31)$ & $1.997(2)$ & $\operatorname{Ir}(1)$ & $\mathrm{N}(4)$ & $2.191(5)$ \\
\hline $\operatorname{Ir}(1)$ & $\mathrm{N}(2)$ & $2.183(2)$ & $\operatorname{Ir}(1)$ & $\mathrm{N}(31)$ & $2.017(5)$ \\
\hline $\operatorname{Ir}(1)$ & $\mathrm{N}(32)$ & $2.199(2)$ & $\operatorname{Ir}(1)$ & $\mathrm{N}(34)$ & $2.198(5)$ \\
\hline $\operatorname{Ir}(1)$ & $\mathrm{C}(45)$ & $1.993(3)$ & $\operatorname{Ir}(1)$ & $\mathrm{C}(1)$ & $1.999(6)$ \\
\hline $\operatorname{Ir}(1)$ & $\mathrm{C}(15)$ & $1.989(3)$ & $\operatorname{Ir}(1)$ & $\mathrm{C}(31)$ & $2.005(7)$ \\
\hline
\end{tabular}

whereas for $\left[\operatorname{Ir}\left(\mathbf{d q x p}^{-}\right)_{2}\right] \mathrm{PF}_{6}$ it is the C-coordinated quinoxaline rings that promote stacking (at $3.677 \AA$ A).

\section{Characterisation of the complexes: spectroscopic studies}

As discussed, the X-ray diffraction studies demonstrated that isolated crystals of the $\operatorname{Ir}(\mathrm{III})$ complexes possessed the cyclometalated coordination sphere. ${ }^{1} \mathrm{H}$ NMR spectroscopic characterization of the bulk samples again supported the isolation of the $\left[\operatorname{Ir}\left(\mathrm{N}^{\wedge} \mathrm{N}^{\wedge} \mathrm{C}\right)_{2}\right]^{+}$isomeric form of each species. For example, $\left[\operatorname{Ir}\left(\mathbf{d q x p}^{-}\right)_{2}\right] \mathrm{PF}_{6}$, each methyl environment becomes inequivalent and were observed between 1.92-2.23 ppm. Three unique aromatic resonances at 8.54, 8.64 and 9.01 ppm (see Fig. S3, ESI $\dagger$ ) were attributed to the loss of symmetry across the bridging pyridyl ring, and a further five quinoxaline-based ${ }^{1} \mathrm{H}$ resonances were observed as singlets at 6.47, 7.03, 7.40, 7.71 and $9.88 \mathrm{ppm}$. The overall loss of one aromatic proton environment versus dqxp2 is due to metalation at the 3-position of one of the quinoxaline moieties. The spectra confirm the asymmetry of the ligand(s) and the inequivalence of the quinoxaline moieties induced by the $\mathrm{N}^{\wedge} \mathrm{N}^{\wedge} \mathrm{C}$ chelating mode. The coordination geometry of $\left[\operatorname{Ir}\left(\mathbf{d q x p} 2^{-}\right)_{2}\right] \mathrm{PF}_{6}$ positions the proton at the 8 position of the quinoxaline ring above the plane of the pyridine ring (Fig. 1; note the larger $\mathrm{N}-\mathrm{Ir}-\mathrm{N}$ trans angle may subtly promote this interaction), which may explain the upfield shift to $6.47 \mathrm{ppm}$.

HRMS was obtained for both complexes and showed the correct mass, and corresponding isotope pattern, for the loss of one $\mathrm{PF}_{6}{ }^{-}$counter ion thus implying a mono-cationic $\left[\operatorname{Ir}\left(\mathbf{d q x p}^{-}\right)_{2}\right]^{+}$fragment.
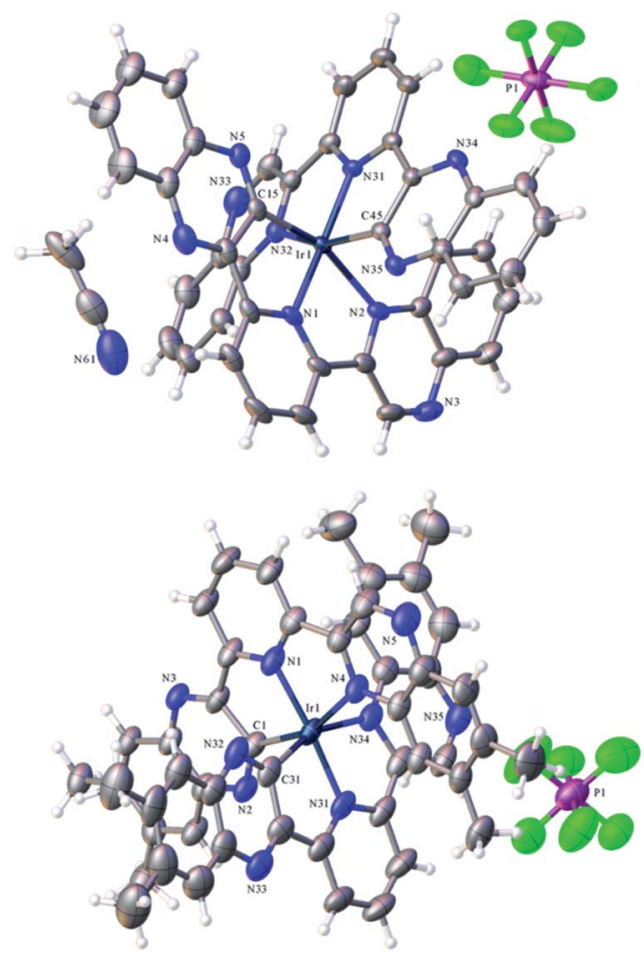

Fig. 1 X-ray crystal structure of $\left[\operatorname{Ir}\left(\operatorname{dqxp1} 1^{-}\right)_{2}\right] \mathrm{PF}_{6}$ (top)and $\left[\operatorname{Ir}\left(\mathbf{d q x p 2} 2^{-}\right)_{2}\right]$ $\mathrm{PF}_{6}$ (bottom). 


\section{Prediction of structures and electronic properties using} computational studies

An initial investigation using computational DFT approaches compared the two coordination modes that were deemed feasible for the ligand-metal combination. Thus, two hypothetical structures (using dqxp1) were calculated that compared the relative energies of the $\left[\operatorname{Ir}\left(\mathrm{N}^{\wedge} \mathrm{N}^{\wedge} \mathrm{N}\right)_{2}\right]^{3+}\left\{c f\right.$. $\left.\left[\operatorname{Ir}(\text { terpy })_{2}\right]^{3+}\right\}$ and $\left[\operatorname{Ir}\left(\mathrm{N}^{\wedge} \mathrm{N}^{\wedge} \mathrm{C}\right)_{2}\right]^{+}$coordination isomers (Fig. S4, ESI $\dagger$ ). The data for each functional used (B3LYP/SDD, B3LYP/LANL2DZ, M062X/ LANL2DZ) is tabulated in the ESI (Tables S3-S5 $\dagger$ ). In summary, the calculated energies are similar for both isomers, but for each functional deployed it was noted that the $\left[\operatorname{Ir}\left(\mathrm{N}^{\wedge} \mathrm{N}^{\wedge} \mathrm{N}\right)_{2}\right]^{3+}$ structure was predicted to be more energetically favourable.

The experimental X-ray diffraction determination of the structural characteristics of both Ir(III) complexes provided the ideal benchmark against which to verify the density functional theory (DFT) approaches used to help describe the electronic properties of the two complexes. The geometry optimization of the two complexes were carried out for both their lowest singlet and triplet states at the DFT (B3LYP/SDD,6-31G* level of theory), with an implicit $\mathrm{CHCl}_{3}$ solvent (IEFPCM). All optimisations were confirmed as minima through harmonic vibrational frequency calculations.

The optimized geometries of both complexes obtained by DFT are shown in Fig. 2. The calculated bond lengths for the studied complexes are in good agreement with their corresponding X-ray crystallographic values, with an average deviation of less than $0.05 \AA$ (Table S6, ESI $\dagger$ ). Typically, the optimised bond lengths were slightly longer in comparison with the experimental data, which might be because the DFT calculations were carried out in implicit solvent while the experimental data were recorded in solid state.

To investigate the effect of terdentate ligands on the electronic structures, molecular orbital decomposition analyses were performed on both complexes using the GaussSum software package. Each ligand was divided into three separate moieties, the C-quinoxaline (R3), $N$-quinoxaline (R1) and
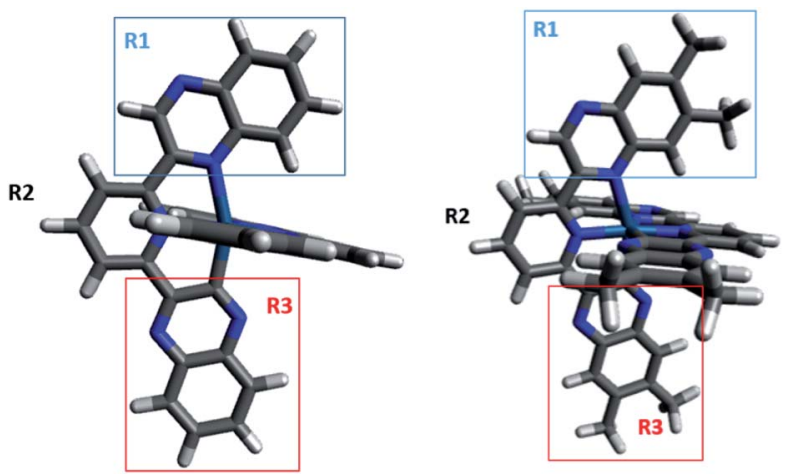

Fig. 2 Optimized geometries of $\left[\operatorname{lr}\left(\operatorname{dqxp} 1^{-}\right)_{2}\right] P F_{6} \quad$ (left) and $\left[\operatorname{lr}\left(\text { dqxp2 } 2^{-}\right)_{2}\right] P F_{6}$ (right). The two complexes have three moieties highlighted, each of which is used to provide a more effective molecular orbital decomposition of the system (R1 $=N$-quinoxaline; R2 = pyridine; R3 = C-quinoxaline). pyridinyl groups (R2), with the iridium metal core constituting its own group. This enabled a more in-depth examination of the complex contributions when compared to treating each whole ligand as an individual group. The results of the decomposition analysis for the frontier orbitals of the singlet ground state for both complexes with each of the ligand groups labelled are shown in Tables 2 and 3; renderings of the frontier molecular orbitals of the $\left[\operatorname{Ir}\left(\mathbf{d q x p}^{-}\right)_{2}\right] \mathrm{PF}_{6}$ complex are shown in Fig. 3 (the equivalent information for $\left[\operatorname{Ir}\left(\mathbf{d q x p 2} 2^{-}\right)_{2}\right] \mathrm{PF}_{6}$ is shown in Tables S7 and S8, ESI $\dagger$ ).

Consistent with previously reported 2-phenylquinoxaline Ir(III) complexes, ${ }^{20}$ the HOMO in both complexes is constructed principally of the contributions from the Ir d-orbital and $\pi$ orbitals of both ligands, located predominantly on the Cquinoxaline moieties. This is in contrast with the LUMO, localized largely on the $N$-quinoxaline moieties, with a contribution from pyridyl moieties. It is noteworthy (from Tables 2 and $\mathrm{S} 7 \dagger)$ that the two ligands in the $\left[\operatorname{Ir}\left(\mathbf{d q x p}^{-}\right)_{2}\right] \mathrm{PF}_{6}$ complexes are predicted to be functionally degenerate, with contribution values falling within a few percentage points of each other, where they differ at all, for any given orbital.

TD-DFT using CAM-B3LYP functional and stationary point calculations were carried out on the two complexes with the aim of computing and analysing the experimentally observed absorption and emission bands. The vertical and adiabatic spin-forbidden transitions of the complexes were estimated, based on the optimized singlet ground state and triplet excitedstate geometries, and the results are shown in Table 3. The first five singlet-to-singlet transitions of the complexes derived from the singlet geometry are reported below in Tables 4 and S8. $\dagger$

The calculated spin-forbidden vertical absorption transitions fall in a similar region as previously studied 2-phenylquinoxaline $\operatorname{Ir}(\mathrm{III})$ complexes, ${ }^{20}$ suggesting that the shoulder peak observed at the longer wavelengths $(>425 \mathrm{~nm})$ in the experimental UV-vis absorption spectra are due to direct photoexcitation to lower lying triplet state(s). Similarly, the vertical and adiabatic emission estimations are a good match for experiment, with predicted wavelengths occurring within the same region as the complex emission spectra, supporting

Table 2 The decomposition analysis of the singlet ground state frontier orbitals of $\left[\operatorname{lr}\left(\mathbf{d q x p} 1^{-}\right)_{2}\right]^{+}$

\begin{tabular}{|c|c|c|c|c|c|c|c|}
\hline \multirow[b]{3}{*}{ Orbital } & \multicolumn{7}{|c|}{ Moiety contribution to orbital (\%) } \\
\hline & \multirow[b]{2}{*}{ Ir $5 d$} & \multicolumn{3}{|l|}{ Q1 } & \multicolumn{3}{|l|}{$\mathrm{Q} 2$} \\
\hline & & $\mathrm{R} 1$ & $\mathrm{R} 2$ & R3 & $\mathrm{R} 1$ & $\mathrm{R} 2$ & $\mathrm{R} 3$ \\
\hline $\mathrm{LUMO}+4$ & 1 & 33 & 15 & 0 & 34 & 15 & 0 \\
\hline LUMO+3 & 1 & 0 & 21 & 28 & 0 & 21 & 28 \\
\hline $\mathrm{LUMO}+2$ & 1 & 1 & 19 & 29 & 1 & 20 & 29 \\
\hline LUMO+1 & 4 & 38 & 11 & 0 & 35 & 10 & 0 \\
\hline LUMO & 4 & 34 & 12 & 1 & 37 & 13 & 1 \\
\hline HOMO & 29 & 2 & 3 & 30 & 2 & 3 & 30 \\
\hline HOMO-1 & 8 & 3 & 3 & 38 & 3 & 4 & 40 \\
\hline HOMO-2 & 10 & 2 & 5 & 40 & 2 & 4 & 37 \\
\hline HOMO-3 & 6 & 1 & 3 & 42 & 1 & 4 & 43 \\
\hline HOMO-4 & 7 & 3 & 4 & 39 & 3 & 4 & 39 \\
\hline
\end{tabular}


Table 3 Computed values for the absorption and emission maxima of the two Ir(III) complexes

\begin{tabular}{llll}
\hline Complex & $\begin{array}{l}\mathrm{S}_{0} \rightarrow \\
\mathrm{T}_{n} \text { Abs. }(\mathrm{nm})\end{array}$ & $\begin{array}{l}\text { Vertical } \mathrm{T}_{1} \rightarrow \\
\mathrm{S}_{0} \text { Em. }(\mathrm{nm})\end{array}$ & $\begin{array}{l}\text { Adiabatic } \mathrm{T}_{1} \rightarrow \\
\mathrm{S}_{0} \text { Em. }(\mathrm{nm})\end{array}$ \\
\hline$\left[\operatorname{Ir}\left(\mathbf{d q x p 1}^{-}\right)_{2}\right]^{+}$ & 513 & 698 & 581 \\
{$\left[\operatorname{Ir}\left(\text { dqxp2 }^{-}\right)_{2}\right]^{+}$} & 527 & 689 & 587
\end{tabular}

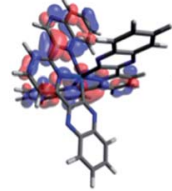

เUMO
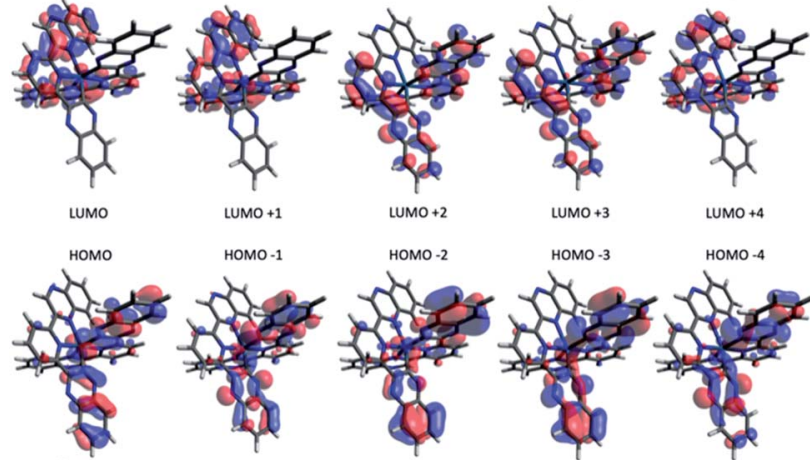

LUMO +3

LUMO +4
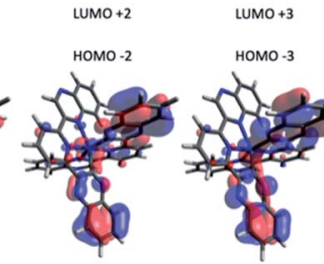

Fig. 3 Renderings of the frontier molecular orbitals of the $\left[\operatorname{lr}\left(\operatorname{dqxp} 1^{-}\right)_{2}\right]$ $\mathrm{PF}_{6}$ complex.

Table 4 The wavelength, oscillator strengths and molecular orbital contributions for the first five singlet-to-singlet excited states for $\left[\operatorname{lr}\left(\mathbf{d q x p} 1^{-}\right)_{2}\right] \mathrm{PF}_{6}$. Molecular orbital contributions less than $10 \%$ have been omitted for clarity

\begin{tabular}{lll}
\hline & Transition & Contributing MOs \\
\hline 1 & $383.91 \mathrm{~nm}, f=0.0099$ & HOMO $\rightarrow$ LUMO $(77 \%)$ \\
2 & $383.64 \mathrm{~nm}, f=0.0179$ & HOMO $\rightarrow$ LUMO+1 $(75 \%)$ \\
3 & $354 \mathrm{~nm}, f=0.0011$ & HOMO $-5 \rightarrow$ LUMO+3 $(29 \%)$ \\
& & HOMO $-4 \rightarrow$ LUMO+2 $(47 \%)$ \\
4 & $352.64 \mathrm{~nm}, f=0.0007$ & HOMO-5 $\rightarrow$ LUMO+2 $(36 \%)$ \\
& & HOMO-4 $\rightarrow$ LUMO+3 $(40 \%)$ \\
5 & $350.12 \mathrm{~nm}, f=0.0067$ & HOMO-7 $\rightarrow$ LUMO+1 $(12 \%)$ \\
& & HOMO-6 $\rightarrow$ LUMO $(40 \%)$
\end{tabular}

the assignment of the long-lived emission feature being spinforbidden in nature. The calculated adiabatic band positions provide a reasonable quantitative match for the experimentally determined values.

The lowest energy transitions expected from the spinallowed component of the UV-vis absorption spectra extend only as far as $380-390 \mathrm{~nm}$, in keeping with the assignment of spin-forbidden vertical transitions accounting for the longer wavelength absorption bands ( $400 \mathrm{~nm}<\lambda<500 \mathrm{~nm}$ ). The predicted magnitude of spin-forbidden absorption appears to be more significant in these tridentate complexes than in related 2phenylquinoxaline $\operatorname{Ir}(\mathrm{III})$ complexes, ${ }^{20}$ given the relatively high intensity of absorption beyond the wavelengths that are ascribed to singlet-singlet processes. Combinations of these results with the decomposition analysis show that the first and second transitions are composed of charge transfer from the Ir centre and R3 ligand component, to the R1 and R2 moieties, which can thus be described in terms of mixed MLCT/ILCT/
LLCT character. The low oscillator strengths of these early transitions are likely due to the minimal wavefunction overlap expected between the R3 moiety and the R1 and R2 moieties due to their spatial separation.

\section{Photophysical properties}

Firstly, the UV-vis absorption spectra of the ligands were obtained in EtOH (see Fig. S5, ESI $\dagger$ ) and show two primary features: an intense sharp feature around $260 \mathrm{~nm}$ and a weaker, broader band with a hint of vibronic coupling at 300-375 nm. Both bands are slightly bathochromically shifted for dqxp2. In both cases these bands are attributed to various spin-allowed, intra-ligand transitions that are likely to be $\pi \rightarrow \pi^{*}$ in nature.

In comparison the spectra of the complexes (Fig. 4), suggest that the absorption bands $300 \mathrm{~nm}<\lambda<370 \mathrm{~nm}$ can be ascribed to ligand centred transitions, with some contribution likely from metal-to-ligand charge transfer (MLCT) transitions. Consistent with prior literature, the feature between $350 \mathrm{~nm}<\lambda$ $<420 \mathrm{~nm}$ can be tentatively assigned as arising from spinallowed ${ }^{1} \mathrm{MLCT} /{ }^{1} \mathrm{ILCT} /{ }^{1} \mathrm{LLCT}$ transitions, as supported by DFT. Both complexes show a prominent feature in the region $350 \mathrm{~nm}<\lambda<400 \mathrm{~nm}$, which has a shoulder feature extending to approximately $550 \mathrm{~nm}$. This shoulder contains a visible lowintensity feature in both cases, that is ascribed to spinforbidden singlet-triplet absorptions, likely ${ }^{3}$ MLCT in nature, as discussed earlier in the DFT investigation. As with the free ligands, the effect of methylation on the quinoxaline backbone is to bathochromically shift all the main absorption features of $\left[\operatorname{Ir}\left(\mathbf{d q x p 2}^{-}\right)_{2}\right] \mathrm{PF}_{6}$.
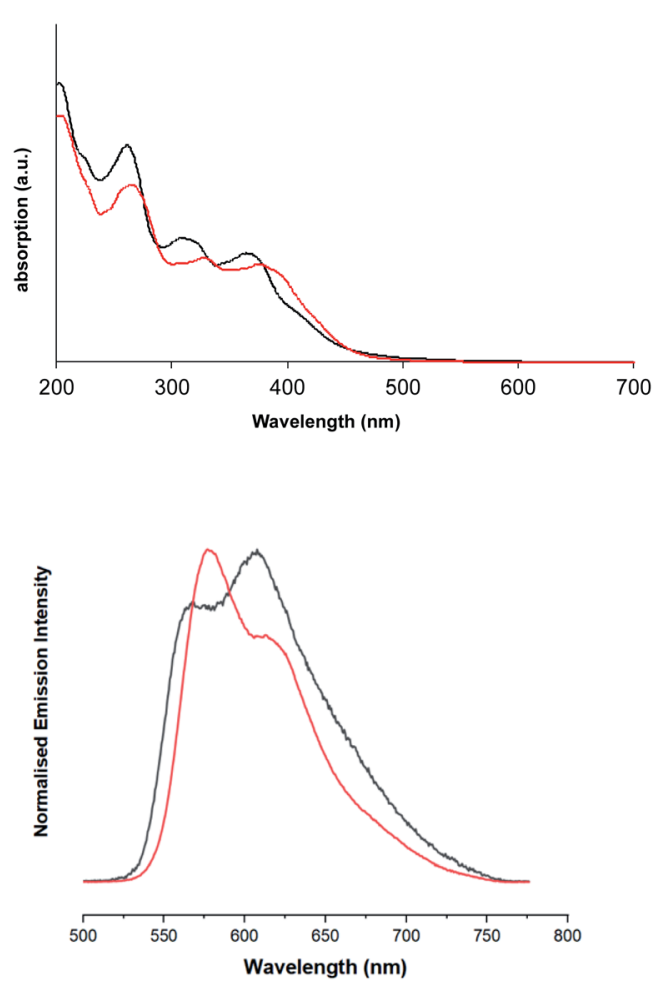

Fig. 4 Solution state UV-vis absorption (top) and emission (bottom) spectra of $\left[\operatorname{lr}\left(\text { dqxp1 }^{-}\right)_{2}\right] \mathrm{PF}_{6}$ complex (black), and $\left[\operatorname{lr}\left(\text { dqxp2 }^{-}\right)_{2}\right] P F_{6}$ complex (red). 
Upon excitation at $355 \mathrm{~nm}$, the emission properties (aerated $\mathrm{CHCl}_{3}$ ) of the complexes (Fig. 4 and Table 5) display a broad luminescence feature around 580-615 $\mathrm{nm}$. In both cases this peak possesses some vibronic structure. The relative intensities of the two main features of the peak are inverted when the methyl substituents are present. Total emission spectra for both complexes were also recorded (Fig. 5) at $77 \mathrm{~K}$ in a solvent glass (3:1 EtOH : $\mathrm{MeOH}$ ) and show much more pronounced resolution of the vibronic progression. Under identical conditions, the free ligands display vibronically structured emission features consistent with an intra-ligand ${ }^{3}\left(\pi-\pi^{*}\right)$ emitting state.

A comparison of the spectra for $\mathbf{d q x p} 2$ and $\left[\operatorname{Ir}\left(\mathbf{d q x p} 2^{-}\right)_{2}\right] \mathrm{PF}_{6}$ clearly shows a close spectral resemblance to the vibronic progression, which presumably belongs to the quinoxalinecentred vibrational modes, but one which is accompanied by a significant bathochromic shift upon coordination to $\operatorname{Ir}(\mathrm{III})$. Interestingly, the appearance of the room temperature emission band was also sensitive to concentration; increasing the concentration of the complex resulted in a general bathochromic shift and a broadening of the peak (Fig. S6, ESI $\dagger$ ). Solvatochromic studies were also undertaken revealing a small variance in emission properties as a function of solvent polarity (see Tables S9 and S10, ESI $\dagger$ ). This confirms that although MLCT character is likely to contribute the transition is mainly ligand-based and may not result in a strong change in dipole moment. In aerated solution $\left[\operatorname{Ir}\left(\mathbf{d q x p} \mathbf{1}^{-}\right)_{2}\right] \mathrm{PF}_{6}$ and $\left[\operatorname{Ir}\left(\mathbf{d q x p} 2^{-}\right)_{2}\right]$ $\mathrm{PF}_{6}$ displayed observed lifetimes of 410 and $662 \mathrm{~ns}$, respectively. These lifetimes were extended to around 1 microsecond under deoxygenated conditions, consistent with a phosphorescent emitting state.

It is pertinent to compare these data with related biscyclometalated complexes of cationic Ir(III) with 2-phenylquinoxaline (2-pqx) ligands, $\left[\operatorname{Ir}(2 \text {-pqx })_{2}(\text { bipy })\right]^{+}$, recorded under similar conditions. ${ }^{20 b}$ The emission maxima and lifetimes are broadly comparable between the two classes of compound, however the luminescence spectral profiles are slightly different: the $\left[\operatorname{Ir}(2 \text {-pqx })_{2} \text { (bipy) }\right]^{+}$species possess broad featureless emission profiles attributed to ${ }^{3} \mathrm{MLCT} /{ }^{3} \mathrm{ILCT}$ character (the LUMO is predicted to be based upon the quinoxaline moiety not the bipy ligand). Despite comparable spectral data, the predicted HOMO and LUMO contributions are subtly different for the archetypal bis-cyclometalated cationic complex [Ir(ppy)(bipy) $]^{+}$, which also shows a broad featureless emission profile $\left(\lambda_{\text {em }} 602 \mathrm{~nm}, \phi_{\text {em }} 9.3 \%, \tau_{\text {obs }} 275 \mathrm{~ns}\right.$ in aerated MeCN). ${ }^{7}$ The HOMO of $\left[\operatorname{Ir}(\text { ppy)(bipy) }]^{+}\right.$has both Ir and phenyl contributions and the LUMO is localised solely on the ancillary bipy ligand resulting in a predicted ${ }^{3} \mathrm{MLCT} /{ }^{3} \mathrm{LLCT}$ mixture to the emissive character. As discussed earlier, $\left[\operatorname{Ir}(\text { terpy })_{2}\right]^{3+}$ is therefore different, with a highly structured blue-green phosphorescence

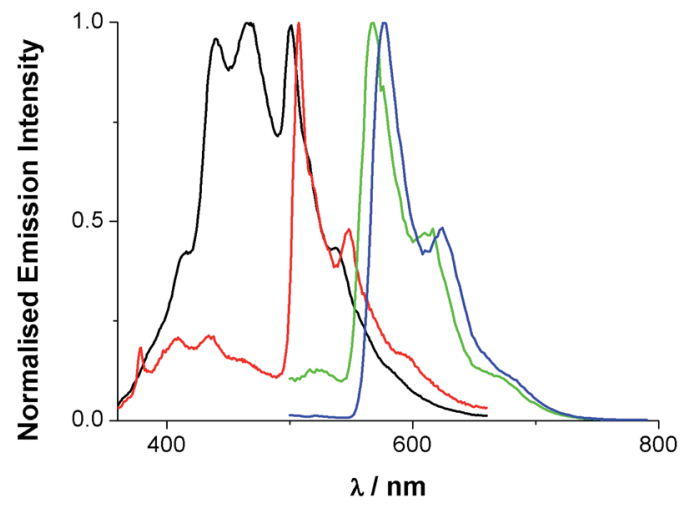

Fig. 5 Total emission spectra of dqxp1 (black), dqxp2 (red), $\left[\operatorname{lr}\left(\mathbf{d q x p} 1^{-}\right)_{2}\right] \mathrm{PF}_{6}$ (green) and $\left[\operatorname{lr}\left(\mathbf{d q x p} 2^{-}\right)_{2}\right] \mathrm{PF}_{6} \quad$ (blue) in $3: 1$ $\mathrm{EtOH}: \mathrm{MeOH}$ glass at $77 \mathrm{~K}\left[\lambda_{\text {exc }}=340\right.$ (ligand), $400 \mathrm{~nm}$ (complex)].

emission band which is attributed to a ligand-centred triplet excited state.

\section{Time-resolved transient absorption spectroscopy}

The two complexes present similar transient absorption spectra, shown in Fig. 6, with a set of features that compare to our previous reports on related 2-phenylquinoxaline complexes of $\operatorname{Ir}(\mathrm{III}) .{ }^{20}$ Both complexes exhibit a strong ground state bleach $350 \mathrm{~nm}<\lambda<425 \mathrm{~nm}$, showing good onset and peak maximum agreement with their respective absorption spectra.

The increases in optical density observed $450 \mathrm{~nm}<\lambda<$ $525 \mathrm{~nm}$ in the $\left[\operatorname{Ir}\left(\mathbf{d q x p 1}^{-}\right)_{2}\right] \mathrm{PF}_{6}$ complex and $475 \mathrm{~nm}<\lambda<$ $600 \mathrm{~nm}$ in the $\left[\operatorname{Ir}\left(\mathbf{d q x p 2}^{-}\right)_{2}\right] \mathrm{PF}_{6}$ complex are both assigned to

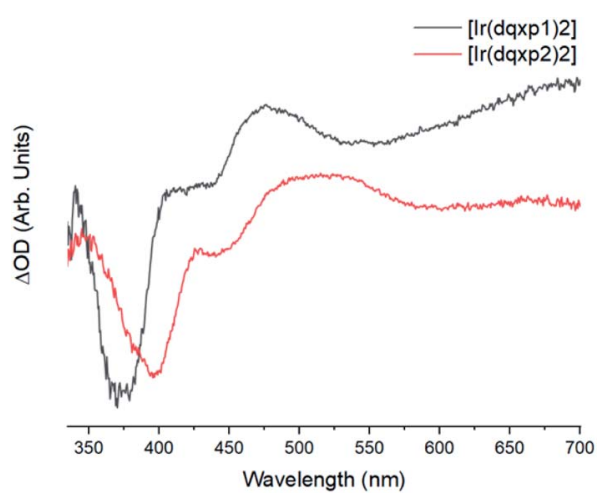

Fig. 6 Background and fluorescence subtracted transient absorption spectra of the two complexes in chloroform, $\lambda_{\text {exc }}=355 \mathrm{~nm}$, with $\left[\operatorname{lr}\left(\text { dqxp1 } 1^{-}\right)_{2}\right] P F_{6}($ black $)$ and $\left[\operatorname{lr}\left(\text { dqxp2 }^{-}\right)_{2}\right] \mathrm{PF}_{6}($ red $)$.

Table 5 Photophysical properties of the $\operatorname{Ir}\left(\right.$ III) complexes $^{a}$

\begin{tabular}{lllc}
\hline Complex $^{a}$ & $\lambda_{\text {abs }}\left(\varepsilon \times 10^{4} / \mathrm{M}^{-1} \mathrm{~cm}^{-1}\right) / \mathrm{nm}$ & $\lambda_{\mathrm{em}}{ }^{b} / \mathrm{nm}$ & $\tau_{\mathrm{obs}}{ }^{b} / \mathrm{ns}$ \\
\hline$\left[\operatorname{Ir}\left(\mathbf{d q x p 1}^{-}\right)_{2}\right] \mathrm{PF}_{6}$ & $267(9.0), 318 \operatorname{sh}(5.2), 367(4.5)$ & 610 & 410 \\
{$\left[\operatorname{Ir}(\mathbf{d q x p 2})_{2}\right] \mathrm{PF}_{6}$} & $273(7.1), 334(4.2), 378(3.9)$ & 580 & 3 \\
\end{tabular}

${ }^{a}$ In aerated chloroform. ${ }^{b}$ Excitation at $355 \mathrm{~nm} .{ }^{c}$ Using $\left[\mathrm{Ru}(\text { bipy })_{3}\right]\left(\mathrm{PF}_{6}\right)_{2}$ as standard $(1.6 \%$ in aerated $\mathrm{MeCN}) .{ }^{25}$ 


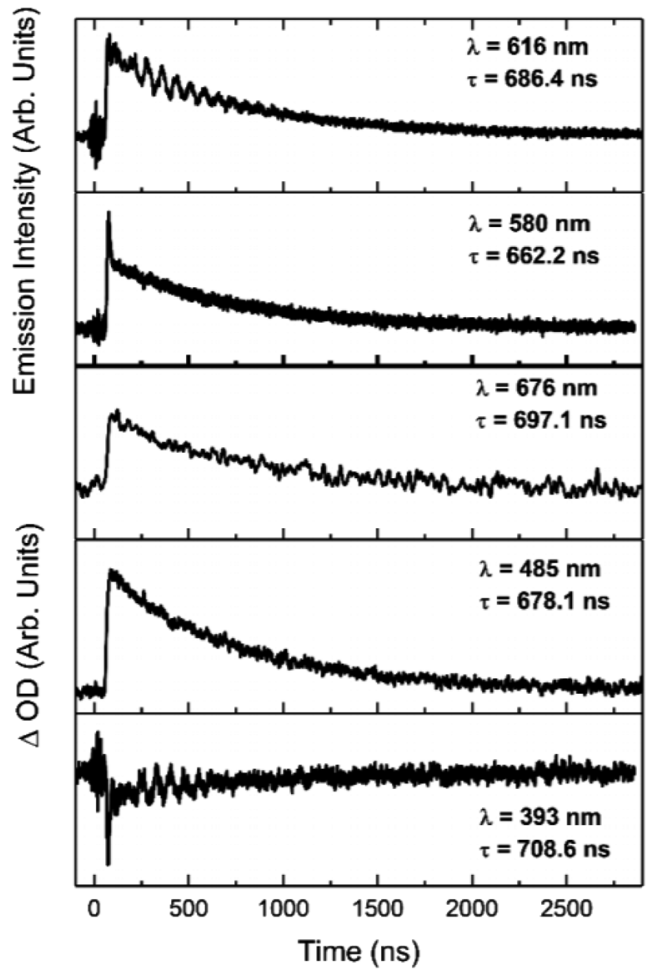

Fig. 7 Kinetic traces of the major features of the transient spectra of [Ir(dqxp2 $\left.\left.{ }^{-}\right)_{2}\right]_{P F_{6}}$ in chloroform at room temperature, aerated. Wavelengths and lifetimes of each trace are inset.

triplet-to-triplet excited state absorption (ESA) bands. These absorption bands are likely predominantly MLCT and ILCT in origin. Both complexes also display a broad, structureless increase in optical density in the longer wavelength region of their spectra, significantly more pronounced in the case of the $\left[\operatorname{Ir}\left(\mathbf{d q x p} \mathbf{1}^{-}\right)\right] \mathrm{PF}_{6}$ complex. Similarly, both are assigned to tripletto-triplet ESA, perhaps arising from transitions from $\mathrm{T}_{n>1}$. Each feature, including the ground state bleach and the long wavelength ESA bands exhibit similar lifetimes (Fig. 7) suggesting that all the features correlate with the same photoexcitation, ISC process and subsequent deactivation.

\section{Conclusions}

We have reported two new 2,6-bis-quinoxalinylpyridine terdentate ligands that should be considered as structural analogues of terpyridine. Working towards these ligands identified dioxane-dibromide as an excellent and selective brominating agent to yield the key intermediate, 2,6-bis(bromoacetyl)pyridine, in multigram scale. The ready availability of this intermediate potentially provides an important building block to other new multidentate ligands that should find important uses in coordination chemistry and its myriad applications. Upon coordination with $\operatorname{Ir}(\mathrm{III})$, structural and spectroscopic studies clarified that the ligands coordinate in a terdentate manner, via cyclometalation, yielding monocationic complexes. This renders the ligands in an unsymmetrical arrangement at $\operatorname{Ir}(\mathrm{III})$, giving both C-coordinated and $\mathrm{N}$-coordinated quinoxaline donors. The site of Ir-C bond formation is of interest as it is in the 3-position of the quinoxaline ring and thus adjacent to one of the ring nitrogen atoms. We noted that supporting computational DFT studies predicted that there was no energetic preference for the $\mathrm{N}^{\wedge} \mathrm{N}^{\wedge} \mathrm{C}$ mode over the $\mathrm{N}^{\wedge} \mathrm{N}^{\wedge} \mathrm{N}\left\{c f\right.$. $\left.\left[\operatorname{Ir}(\text { terpy })_{2}\right]\left(\mathrm{PF}_{6}\right)_{3}\right\}$ coordination mode.

The isolated $\operatorname{Ir}(\mathrm{III})$ complexes are photoluminescent, displaying moderately structured emission in the orange-red region of the spectrum, which was characterized as a phosphorescence of ${ }^{3} \mathrm{MLCT} /{ }^{3} \mathrm{ILCT}$ character. Supporting DFT studies suggest that the HOMO likely comprises contributions from the Ir $5 \mathrm{~d}$ orbitals and the C-coordinated quinoxaline moiety; the LUMO is likely to be dominated by the N-coordinated quinoxaline unit. Thus, functionalisation of the bis-quinoxalinyl units provides some opportunity for tuning the photophysical attributes of these species.

Of course, given the breadth and importance of coordination chemistry demonstrated by $2,2^{\prime}: 6^{\prime}, 2^{\prime \prime}$-terpyridine(s), the new bisquinoxalinyl analogues described herein clearly merit further investigation with a range of different metal ions.

\section{Experimental}

All reactions were performed with the use of vacuum line and Schlenk techniques. Reagents were commercial grade and were used without further purification. ${ }^{1} \mathrm{H}$ and ${ }^{13} \mathrm{C}\left\{{ }^{1} \mathrm{H}\right\}$ NMR spectra were obtained on a Bruker Avance dpx 400 spectrometer, and were recorded in $\mathrm{CDCl}_{3}$, or $\mathrm{CD}_{3} \mathrm{CN}$ solutions. ${ }^{1} \mathrm{H},{ }^{13} \mathrm{C}$ $\left\{{ }^{1} \mathrm{H}\right\}$ chemical shifts $(\delta)$ were determined relative to internal tetramethylsilane, $\mathrm{Si}\left(\mathrm{CH}_{3}\right)_{4}$ and are given in ppm. Lowresolution mass spectra were obtained by the staff at Cardiff University. High-resolution mass spectra were carried out by the staff at Cardiff University and the EPSRC National Mass Spectrometry Service at Swansea University, UK. Photophysical data was obtained on a Jobin Yvon-Horiba Fluorolog-3 spectrometer fitted with a JY TBX picosecond photodetection module in $\mathrm{CHCl}_{3}$ The pulsed source was a $355 \mathrm{~nm}$ output. Luminescence lifetime profiles were obtained using the Jobin Yvon - Horiba FluoroHub single photon counting module and the data fits yielded the lifetime values using the provided DAS6 deconvolution software. Quantum yields using $\left[\mathrm{Ru}(\text { bipy })_{3}\right]\left(\mathrm{PF}_{6}\right)_{2}$ as standard $(1.6 \% \text { in aerated } \mathrm{MeCN})^{25}$ and the following equation:

$$
\Phi_{\mathrm{i}}=\Phi_{\mathrm{R}}\left(\frac{I_{\mathrm{i}}}{I_{\mathrm{R}}}\right)\left(\frac{A_{\mathrm{R}}}{A_{\mathrm{i}}}\right)\left(\frac{n_{\mathrm{i}}{ }^{2}}{n_{\mathrm{R}}{ }^{2}}\right)
$$

IR spectra were recorded on an ATR equipped Shimadzu IRAffinity-1 spectrophotometer. UV-vis data were recorded as solutions on a PerkinElmer Lamda 20 spectrophotometer.

\section{X-ray crystallography}

Data collection and processing. Suitable crystals of $\left[\operatorname{Ir}\left(\mathbf{d q x p} 1^{-}\right)_{2}\right] \mathrm{PF}_{6}$ and $\left[\operatorname{Ir}\left(\mathbf{d q x p 2}^{-}\right)_{2}\right] \mathrm{PF}_{6}$ were selected and data collected following a standard method. ${ }^{26}$ In each case, a crystal was selected and mounted on a MITIGEN holder in 
perfluoroether oil on either a Rigaku FRE+ diffractometer equipped with VHF Varimax confocal mirrors and an AFC12 goniometer and HyPix 6000 detector (for $\left.\left[\operatorname{Ir}\left(\mathbf{d q x p}^{-}\right)_{2}\right] \mathrm{PF}_{6}\right)$ or a Rigaku $007 \mathrm{HF}$ diffractometer equipped with Varimax confocal mirrors and an AFC11 goniometer and HyPix 6000 detector (for $\left.\left[\operatorname{Ir}\left(\mathbf{d q x p}^{-}\right)_{2}\right] \mathrm{PF}_{6}\right)$. The crystals were kept at a steady $T=100(2) \mathrm{K}$ during data collection using an Oxford Cryosystems lowtemperature device. The structures were solved with the ShelXT ${ }^{27}$ structure solution program using the intrinsic phasing solution method and by using Olex2 (ref. 28) as the graphical interface. The models were refined with version 2018/3 of ShelXL ${ }^{29}$ using Least squares minimisation. CCDC 2101342 and 2101343 contains ESI X-ray crystallographic data for $\left[\operatorname{Ir}\left(\mathbf{d q x p}^{-}\right)_{2}\right] \mathrm{PF}_{6}$ and $\left[\operatorname{Ir}\left(\mathbf{d q x p}^{-}\right)_{2}\right] \mathrm{PF}_{6}$ respectively. $\dagger$

Transient absorption measurements. Transient absorption measurements were carried out using an Edinburgh instruments LP920 spectrometer. All spectra were collected using a pump wavelength of $355 \mathrm{~nm}$ (third harmonic of a Continuum Surelite II Nd:YAG laser system). The probe light for these measurements was a xenon lamp, affording spectral generation between $300<\lambda<800 \mathrm{~nm}$. Wavelength dependent spectra were recorded with a $2.05 \mathrm{~nm}$ spectral resolution, collected using an Andor ICCD camera, and integrated over the first $500 \mathrm{~ns}$ after the pump laser pulse. The spectra are presented as $\Delta \mathrm{OD}_{\mathrm{Xe}}$ lamp, which is simply referred to as $\Delta \mathrm{OD}$. Lifetime data was generated using a photomultiplier to collect time resolved signals, with the bandwidth of these data being identical to the camera resolution $(2.05 \mathrm{~nm})$. The lifetime data is fit using the Origin 2017 software package, and each data set is fit using a monoexponential function, with no evidence of multiexponential components. Uncertainties in lifetimes are taken from the leastsquares fitting algorithm, and are not indicative of the uncertainties in multiple fits or data sets.

\section{Computational methods}

Electronic structure calculations were all performed using density fitted-density functional theory within the Gaussian 09 computational chemistry suite. ${ }^{30}$ All calculations were performed using the Stuttgart-Dresden (SDD) effective core potential and basis set in the treatment of the iridium, in combination with a $6-31 \mathrm{G}^{*}$ basis set for all other light atoms. Full geometry optimizations were performed for the cationic complexes utilizing the self-consistent reaction field model (SCRF) which treats the solvent implicitly as a dielectric continuum. In all cases the solvent chosen was chloroform, consistent with that utilized in the majority of the spectroscopic measurements. Chloroform is characterized by an electrical permittivity of $\varepsilon=4.7113$ within the calculations. This computational method models the solvent as surrounding a cavity in which the solute resides, and this cavity is characterized using an integral equation formalism for the polarizable continuum model (IEFPCM). This model represents the system in equilibrium during, for example, an optimization routine: in all excited state calculations a non-equilibrium solvent model is used.
All geometry optimizations were performed using an ultrafine grid and very tight convergence criteria, and the minima were confirmed as stationary points through the computation of harmonic vibrational frequencies, each of which showed no imaginary components. These stationary points were used in single point TD-DFT calculations to compute vertical excitation energies. All TD-DFT calculations were undertaken using a linear response approach. All TD-DFT calculations were also performed with a long range corrected hybrid functional (CAMB3LYP).

Phosphorescence and spin-forbidden absorption bands were investigated using unrestricted density functional theory to compute parameters associated with the first triplet state $\left(\mathrm{T}_{1}\right)$, using an identical methodology as for the singlet states. Decomposition of the molecular orbital character was performed using the GaussSum software package. Crystal structure overlays with optimised computational structures has been performed using the Chimera software package, which has also been used to calculate root mean squared deviation (RMSD) values for these comparative structures. ${ }^{31}$

\section{Synthesis}

Synthesis of 2,6-bis(bromoacetyl)pyridine. To a solution of 2,6-diacetylpyridine $(5.0 \mathrm{~g}, 30.6 \mathrm{mmol})$ in dioxane $(20 \mathrm{~mL})$ heated to $60{ }^{\circ} \mathrm{C}$ was added dropwise a suspension of dioxane dibromide $(17.0 \mathrm{~g}, 68.6 \mathrm{mmol})$ in dioxane $(40 \mathrm{~mL})$ over a period of 1 hour. The mixture was maintained at $60{ }^{\circ} \mathrm{C}$ throughout and further stirred at this temperature for 2 hours, upon which the solution was allowed to cool to room temperature. The solvent was removed in vacuo, and ethanol $(15 \mathrm{~mL})$ was added, with the resultant precipitate filtered and washed with ethanol $(10 \mathrm{~mL})$ to yield 2,6-bis(bromoacetyl)pyridine (10.6 g, $20.6 \mathrm{mmol}, 67 \%$ ) as a white crystalline solid. ${ }^{1} \mathrm{H} \mathrm{NMR}\left(400 \mathrm{MHz}, \mathrm{CDCl}_{3}\right) \delta_{\mathrm{H}} 8.24$ $(2 \mathrm{H}, \mathrm{d}, J=7.8, \mathrm{NCCHCH}), 8.06(1 \mathrm{H}, \mathrm{t}, J=7.8, \mathrm{NCCHCH}), 4.78$ $\left(4 \mathrm{H}, \mathrm{s}, \mathrm{COCH}_{2} \mathrm{Br}\right) \mathrm{ppm}$; data agrees with previously published results. ${ }^{21 b}$

Synthesis of dqxp1. To a solution of 2,6-bis(bromoacetyl) pyridine $(1.0 \mathrm{~g}, 3.1 \mathrm{mmol})$ in dioxane $(30 \mathrm{~mL})$ was added $o$ phenylenediamine $(0.84 \mathrm{~g}, 7.8 \mathrm{mmol})$ and the mixture heated to reflux for 16 hours. The reaction was cooled to room temperature, the solvent removed in vacuo and the product purified by column chromatography on silica eluting with DCM and $\mathrm{MeOH}$ (99: 1 and $95: 5)$ to yield dqxp1 as a grey powder $(0.22 \mathrm{~g}$, $0.7 \mathrm{mmol}, 21 \%) .{ }^{1} \mathrm{H}$ NMR (400 MHz, $\left.\mathrm{CDCl}_{3}\right) \delta_{\mathrm{H}} 10.04(2 \mathrm{H}, \mathrm{s})$, $8.60(2 \mathrm{H}, \mathrm{d}, J=7.9 \mathrm{~Hz}), 8.03-8.12(4 \mathrm{H}, \mathrm{m}), 7.99(1 \mathrm{H}, \mathrm{t}, J=7.9$ $\mathrm{Hz}), 7.67-7.72(4 \mathrm{H}, \mathrm{m}) \mathrm{ppm} .{ }^{13} \mathrm{C}\left\{{ }^{1} \mathrm{H}\right\} \mathrm{NMR}\left(101 \mathrm{MHz}, \mathrm{CDCl}_{3}\right) \delta_{\mathrm{C}}$ 154.2, 149.8, 144.2, 142.7, 141.8, 138.4, 130.3, 130.3, 129.7, 129.4, $122.9 \mathrm{ppm}$. HRMS $\mathrm{m} / \mathrm{z}$ found 336.1247 ; calcd 336.1244 for $\left[\mathrm{C}_{21} \mathrm{H}_{14} \mathrm{~N}_{5}\right]^{+}$. UV-vis $\lambda_{\max }(\mathrm{EtOH}) / \mathrm{nm}\left(\varepsilon / \mathrm{dm}^{3} \mathrm{~mol}^{-1} \mathrm{~cm}^{-1}\right) 213$ (20 400), 254 (53 100), 325 sh (20 400), 334 (21 700).

Synthesis of dqxp2. 4,5-Dimethyl-1,2-diaminobenzene (0.64 g, $4.7 \mathrm{mmol}$ ) was added to a solution of 2,6-bis(bromoacetyl)pyridine $(0.5 \mathrm{~g}, 1.6 \mathrm{mmol})$ in dioxane $(15 \mathrm{~mL})$ and treated as above to yield dqxp2 as a grey powder $(0.44 \mathrm{~g}$, $1.1 \mathrm{mmol}, 72 \%) .{ }^{1} \mathrm{H}$ NMR (400 MHz, $\left.\mathrm{CDCl}_{3}\right) \delta_{\mathrm{H}} 10.01(2 \mathrm{H}, \mathrm{s})$, $8.69(2 \mathrm{H}, \mathrm{d}, J=8.0 \mathrm{~Hz}), 8.10(1 \mathrm{H}, \mathrm{t}, J=8.0 \mathrm{~Hz}), 7.95(4 \mathrm{H}$, 
overlapping s), $2.56\left(12 \mathrm{H}\right.$, overlapping s, Me) ppm. ${ }^{13} \mathrm{C}\left\{{ }^{1} \mathrm{H}\right\} \mathrm{NMR}$ $\left(101 \mathrm{MHz}, \mathrm{CDCl}_{3}\right) \delta_{\mathrm{C}} 154.2,149.1,142.9,141.3,141.3,141.1$, 140.7, 138.3, 128.6, 128.0, 122.4, $20.4\left(\mathrm{CH}_{3}\right), 20.3\left(\mathrm{CH}_{3}\right)$ ppm. HRMS $m / z$ found 392.1870 ; calcd 392.1870 for $\left[\mathrm{C}_{25} \mathrm{H}_{22} \mathrm{~N}_{5}\right]^{+}$. UVvis $\lambda_{\max }(\mathrm{EtOH}) / \mathrm{nm}\left(\varepsilon / \mathrm{dm}^{3} \mathrm{~mol}^{-1} \mathrm{~cm}^{-1}\right) 218$ (17 300), 258 (27 900), 343 (13 800), 355 sh (11 800).

Synthesis of the iridium complexes. dqxp1 $(50 \mathrm{mg}, 0.15$ $\mathrm{mmol})$ and $\mathrm{IrCl}_{3} \cdot x \mathrm{H}_{2} \mathrm{O}(44 \mathrm{mg}, 0.15 \mathrm{mmol})$ were suspended in 2-ethoxyethanol $(10 \mathrm{~mL})$ and heated to reflux for 2 hours, after which time the reaction was allowed to cool to room temperature and the resulting precipitate filtered and washed with ethanol and diethyl ether to yield '[ $\left[\operatorname{Ir}(\mathbf{d q x p 1}) \mathrm{Cl}_{3}\right]$ ' (69 mg, $0.11 \mathrm{mmol}, 73 \%$ ) which was used without further purification.

' $\left[\operatorname{Ir}(\mathbf{d q x p 2}) \mathrm{Cl}_{3}\right]$ ' was synthesised in an analogous fashion from dqxp2 $(71 \mathrm{mg}, 0.18 \mathrm{mmol})$ and $\mathrm{IrCl}_{3} \cdot x \mathrm{H}_{2} \mathrm{O}(54 \mathrm{mg}, 0.18$ $\mathrm{mmol}$ ) to yield the title compound as a dark beige solid $(94 \mathrm{mg}$, $0.14 \mathrm{mmol}, 75 \%)$.

Synthesis of $\left[\operatorname{Ir}\left(\mathbf{d q x p 1}^{-}\right)_{2}\right] \mathbf{P F}_{\mathbf{6}} \cdot$ ' $\left[\operatorname{Ir}(\mathbf{d q x p 1}) \mathrm{Cl}_{3}\right]$ ' $(50 \mathrm{mg}, 0.08$ $\mathrm{mmol})$ and a further equivalent of dqxp1 $(26 \mathrm{mg}, 0.08 \mathrm{mmol})$ were suspended in ethylene glycol $(3 \mathrm{~mL})$ and the flask was evacuated and refilled three times with nitrogen. The reaction mixture was heated to reflux in the dark for 2 hours. The mixture was allowed to cool to room temperature and water $(20$ $\mathrm{mL}$ ) was added, heated to $60-70{ }^{\circ} \mathrm{C}$ and saturated aqueous $\mathrm{NH}_{4} \mathrm{PF}_{6}$ was added and cooled. The precipitate was filtered, washed with water and diethyl ether and dried in air. The product was purified by column chromatography on silica eluting with DCM and MeOH (95: 5 followed by $9: 1$ ) and collecting the red band to yield $\left[\operatorname{Ir}\left(\mathbf{d q x p 1 ^ { - }}\right)_{2}\right] \mathrm{PF}_{6}$ as a red solid (16 mg, $0.02 \mathrm{mmol}, 20 \%) .{ }^{1} \mathrm{H}$ NMR $\left(400 \mathrm{MHz}, \mathrm{CDCl}_{3}\right) \delta_{\mathrm{H}} 9.99$ $(1 \mathrm{H}, \mathrm{s}), 9.17(1 \mathrm{H}, \mathrm{dd}, J=1.0,8.3 \mathrm{~Hz}), 8.69(1 \mathrm{H}, \mathrm{dd}, J=0.9,7.9$ Hz), $8.56(1 \mathrm{H}$, app. t, $J=7.9 \mathrm{~Hz}), 7.66-7.71(1 \mathrm{H}, \mathrm{m}), 7.64(1 \mathrm{H}, \mathrm{dd}$, $J=1.3,8.2 \mathrm{~Hz}), 7.36-7.47(2 \mathrm{H}, \mathrm{m}), 7.31-7.33(3 \mathrm{H}, \mathrm{m}), 7.61(1 \mathrm{H}$, $\mathrm{dd}, J=1.1,8.5 \mathrm{~Hz}) \mathrm{ppm} .{ }^{13} \mathrm{C}\left\{{ }^{1} \mathrm{H}\right\}$ NMR $\left(101 \mathrm{MHz}, \mathrm{CDCl}_{3}\right) \delta_{\mathrm{C}}$ $159.5,158.7,154.2,150.7,144.2$, 143.9, 143.7, 141.0, 140.2, 139.9, 134.6, 133.1, 130.7, 130.4, 129.7, 128.4, 127.8, 126.4, $125.3,124.1 \mathrm{ppm}$. HRMS $\mathrm{m} / \mathrm{z}$ found 859.1785 ; calcd 859.1786 for $\left[\mathrm{C}_{42} \mathrm{H}_{24} \mathrm{IrN}_{10}\right]^{+}$. UV-vis $\lambda_{\max }(\mathrm{MeCN}) / \mathrm{nm}\left(\varepsilon / \mathrm{dm}^{3} \mathrm{~mol}^{-1} \mathrm{~cm}^{-1}\right) 267$ (90 000), 318 (52 000), 367 (45 000).

Synthesis of $\left[\operatorname{Ir}\left(\mathbf{d q x p 2}^{-}\right)_{2}\right] \mathbf{P F}_{6} \cdot$ ' $\left[\operatorname{Ir}(\mathbf{d q x p 2}) \mathrm{Cl}_{3}\right] '(70 \mathrm{mg}, 0.10$ $\mathrm{mmol}$ ) and dqxp2 (40 $\mathrm{mg}, 0.10 \mathrm{mmol})$ were treated as above to yield $\left[\operatorname{Ir}\left(\mathbf{d q x p 2}^{-}\right)_{2}\right] \mathrm{PF}_{6}$ as a red solid $(32 \mathrm{mg}, 0.03 \mathrm{mmol}, 28 \%)$. ${ }^{1} \mathrm{H}$ NMR $\left(400 \mathrm{MHz}, \mathrm{CD}_{3} \mathrm{CN}\right) \delta_{\mathrm{H}} 9.88(1 \mathrm{H}, \mathrm{s}), 9.01(1 \mathrm{H}, \mathrm{d}, J=7.9$ $\mathrm{Hz}), 8.64(1 \mathrm{H}, \mathrm{d}, J=7.9 \mathrm{~Hz}), 8.54(1 \mathrm{H}$, app. t, $J=7.9 \mathrm{~Hz}), 7.71$ $(1 \mathrm{H}, \mathrm{s}), 7.40(1 \mathrm{H}, \mathrm{s}), 7.03(1 \mathrm{H}, \mathrm{s}), 6.47(1 \mathrm{H}, \mathrm{s}), 2.23\left(3 \mathrm{H}, \mathrm{s}, \mathrm{CH}_{3}\right)$, $2.14\left(6 \mathrm{H}\right.$, overlapping s, $\left.\mathrm{CH}_{3}\right), 1.92\left(3 \mathrm{H}, \mathrm{s}, \mathrm{CH}_{3}\right) \mathrm{ppm} .{ }^{13} \mathrm{C}\left\{{ }^{1} \mathrm{H}\right\}$ NMR $\left(101 \mathrm{MHz}, \mathrm{CDCl}_{3}\right) \delta_{\mathrm{C}} 160.1,157.7,154.8,154.4,149.6$, 145.4, 144.6, 143.3, 143.1, 142.7, 141.2, 140.2, 139.9, 138.6, 137.8, 129.3, 128.6, 127.8, 125.1, 124.5, 123.3, $20.9\left(\mathrm{CH}_{3}\right), 20.1$ $\left(\mathrm{CH}_{3}\right), 19.9\left(\mathrm{CH}_{3}\right) \mathrm{ppm}$. HRMS $\mathrm{m} / \mathrm{z}$ found 971.3025 ; calcd 971.3038 for $\left[\mathrm{C}_{50} \mathrm{H}_{40} \mathrm{IrN}_{10}\right]^{+}$. UV-vis $\lambda_{\max }(\mathrm{MeCN}) / \mathrm{nm}\left(\varepsilon / \mathrm{dm}^{3}\right.$ $\mathrm{mol}^{-1} \mathrm{~cm}^{-1}$ ) 273 (71 000), 328 (42 000), 376 (39 000).

\section{Conflicts of interest}

There are no conflicts of interest to declare.

\section{Acknowledgements}

The Leverhulme Trust are thanked for funding (RPG-2015-359). The EPSRC National Mass Spectrometry Service at Swansea University is also thanked. Dr Thomas Stonelake is thanked for some initial contributions to the computational work.

\section{Notes and references}

1 (a) Iridium(III) in Optoelectronic and Photonics Applications, ed. E. Zysman-Colman, Wiley, 2017; (b) L. Flamini, A. Barbieri, C. Sabbatini, B. Ventura and F. Barrigelletti, Top. Curr. Chem., 2007, 281, 143.

2 R. Bevernaegie, S. A. M. Wehlin, B. Elias and L. TroianGautier, ChemPhotoChem, 2021, 5, 217.

3 (a) C. E. Housecroft and E. C. Constable, Coord. Chem. Rev., 2017, 350, 155; (b) G.-Y. Chen, B.-R. Chang, T.-A. Shih, C.-H. Lin, C.-L. Lo, Y.-Z. Chen, Y.-X. Liu, Y.-R. Li, J.-T. Guo, C.-W. Lu, Z.-P. Yang and H.-C. Su, Chem.-Eur. J., 2019, 25, 5489; (c) K. Saito, N. Matsusue, H. Kanno, Y. Hamada, H. Takahashi and T. Matsumura, Jpn. J. Appl. Phys., 2004, 43, 2733.

4 Y. You and W. Nam, Chem. Soc. Rev., 2012, 41, 7061.

5 (a) K. K. Lo, M.-W. Louie and K. Zhang, Coord. Chem. Rev., 2010, 254, 2603; (b) Q. Zhao, C. Huang and F. Li, Chem. Soc. Rev., 2011, 40, 2508; (c) C. Caporale and M. Massi, Coord. Chem. Rev., 2018, 363, 71; (d) A. Zamora, G. Vigueras, V. Rodrgiguez, M. D. Santana and J. Ruiz, Coord. Chem. Rev., 2018, 360, 34.

6 F. Monti, A. Baschieri, L. Sambri and N. Armaroli, Acc. Chem. Res., 2021, 54, 1492.

7 S. Ladouceur and E. Zysman-Colman, Eur. J. Inorg. Chem., 2013, 2985.

8 (a) N. P. Ayala, C. M. Flynn Jr, L. Sacksteder, J. N. Demas and B. A. DeGraff, J. Am. Chem. Soc., 1990, 112, 3837; (b) J.-P. Collin, I. M. Dixon, J.-P. Sauvage, J. A. G. Williams, F. Barigelletti and L. Flamigni, J. Am. Chem. Soc., 1999, 121, 5009; (c) S. Titos-Padilla, E. Colacio, S. J. A. Pope, J. J. Delgado, M. Melgosa and J. M. Herrera, J. Mater. Chem. C, 2013, 1, 3808.

9 (a) D. N. Chirdon, W. T. Transue, H. N. Kagalwala, A. Kaur, A. B. Maurer, T. Pintauer and S. Bernhard, Inorg. Chem., 2014, 53, 1487; (b) W. Goodall and J. A. G. Williams, J. Chem. Soc., Dalton Trans., 2000, 2893; (c) A. Prokop, J. A. Czaplewska, M. Clausen, M. Konig, A. Wild, R. Thorwith, B. Schulze, K. Babiuch, D. Pretzel, U. S. Schubert and M. Gottscaldt, Eur. J. Inorg. Chem., 2016, 3480 .

10 (a) S. Campagna, A. Mamo and J. K. Stille, J. Chem. Soc., Dalton Trans., 1991, 2545; (b) A. Mamo, A. Juris, G. Calogero and S. Campagna, Chem. Commun., 1996, 1225.

11 A. Mamo, I. Stefio, M. F. Parisi, A. Credi, M. Venturi, C. D. Pietro and S. Campagna, Inorg. Chem., 1997, 36, 5947.

12 M. Polson, S. Fracasso, V. Bertolasi, M. Ravaglia and F. Scandola, Inorg. Chem., 2004, 43, 1950.

13 (a) A. J. S. Bexon and J. A. G. Williams, C. R. Chim., 2005, 8, 1326; (b) E. V. Puttock, A. Sil, D. S. Yufit and J. A. G. Williams, 
Dalton Trans., 2020, 49, 10463; (c) V. L. Whittle and J. A. Gareth Williams, Inorg. Chem., 2008, 47, 6596.

14 L. L. Tinker and S. Bernhard, Inorg. Chem., 2009, 48, 10507. 15 (a) J. A. G. Williams, A. J. Wilkinson and V. L. Whittle, Dalton Trans., 2008, 2081; (b) Y. Chi, T.-K. Chang, P. Ganesan and P. Rajakannu, Coord. Chem. Rev., 2017, 346, 91; (c) S. Lee and W.-S. Han, Inorg. Chem. Front., 2020, 7, 2396.

16 (a) M. Polson, S. Fracasso, V. Bertolasi, M. Ravaglia and F. Scandola, Inorg. Chem., 2004, 43, 1950; (b) M. Polson, M. Ravaglia, S. Fracasso, M. Garavelli and F. Scandola, Inorg. Chem., 2005, 44, 1282; (c) A. Jacques, T. Auvray, R. Bevernaegie, F. Lpiseau, M. Cibian, G. S. Hanan, A. K.-D. Mesmaeker and B. Elias, Inorg. Chim. Acta, 2018, 471, 8; (d) V. L. Whittle and J. A. G. Williams, Dalton Trans., 2009, 3929; (e) A. Jacque, O. Schott, K. Robeyns, G. S. Hanan and B. Elias, Eur. J. Inorg. Chem., 2016, 1779; (f) F. Tessore, D. Roberto, R. Ugo, M. Pizzotti, S. Quici, M. Cavazzini, S. Bruni and F. De Angelis, Inorg. Chem., 2005, 44, 8967.

17 B. Liu, M. A. Jabed, S. Kilina and W. Sun, Inorg. Chem., 2020, 59, 8532.

18 R. E. Daniels, S. Culham, M. Hunter, M. C. Durrant, M. R. Probert, W. Clegg, J. A. Gareth Williams and V. N. Kozhevnikov, Dalton Trans., 2016, 45, 6949.

19 K. Andrikopoulos, C. Anastasopoulos, J. K. Kallitsis and A. K. Andreapoulou, Polymers, 2020, 12, 2976.

20 (a) E. E. Langdon-Jones, A. J. Hallett, J. D. Routledge, D. A. Crole, B. D. Ward, J. A. Platts and S. J. A. Pope, Inorg. Chem., 2013, 52, 448; (b) K. A. Phillips, T. M. Stonelake, K. Chen, Y. Hou, J. Zhao, S. J. Coles, P. N. Horton, S. J. Keane, E. C. Stokes, I. A. Fallis, A. J. Hallett, S. P. O'Kell, J. B. Beames and S. J. A. Pope, Chem.-Eur. J., 2018, 24, 8577; (c) K. A. Phillips, T. M. Stonelake, P. N. Horton, S. J. Coles, A. J. Hallett, S. P. O'Kell, J. M. Beames and S. J. A. Pope, J. Organomet. Chem., 2019, 893, 11; (d) A. H. Day, M. H. Übler, H. L. Best, E. LloydEvans, R. J. Mart, I. A. Fallis, R. K. Allemann, E. A. H. AlWattar, N. I. Keymer, N. J. Buurma and S. J. A. Pope, Chem. Sci., 2020, 11, 1599; (e) T. M. Stonelake, K. A. Phillips, H. Y. Otaif, Z. C. Edwardson, P. N. Horton, S. J. Coles, J. M. Beames and S. J. A. Pope, Inorg. Chem., 2020, 59, 2266; ( $f$ ) S. A. Fitzgerald, H. Y. Otaif, C. E. Elgar, N. Sawicka, P. N. Horton, S. J. Coles, J. M. Beames and S. J. A. Pope, Inorg. Chem., 2021, 60, 15467.

21 (a) X.-N. Cao, X.-M. Wan, F.-L. Yang, K. Li, X.-Q. Hao, T. Shao, X. Zhu and M.-P. Song, J. Org. Chem., 2018, 83, 3657; (b)
M. Okai, K. Takahashi, T. Sakurai, H. Ohta, T. Yamamoto and Y. Einaga, J. Mater. Chem. C, 2015, 3, 7858; (c) K. Li, J.-L. Niu, M.-Z. Yang, Z. Li, L.-Y. Wu, X.-Q. Hao and M.-P. Song, Organometallics, 2015, 34, 1170; (d) A. T. Baker and H. A. Goodwin, Aust. J. Chem., 1986, 39, 209.

22 S. K. Chaudhuri, S. Roy and S. Bhar, Beilstein J. Org. Chem., 2012, 8, 323.

23 J.-P. Collin, I. M. Dixon, J.-P. Sauvage, J. A. G. Williams, F. Barigelletti and L. Flamigni, J. Am. Chem. Soc., 1999, 121, 5009.

24 N. Yoshikawa, S. Yamabe, N. Kanehisa, Y. Kai, H. Takashima and K. Tsukahara, Eur. J. Inorg. Chem., 2007, 1911.

25 M. Frank, M. Nieger, F. Vogtle, P. Belser, A. von Zelewsky, L. De Cola, V. Balzani, F. Barigelletti and L. Flamigni, Inorg. Chim. Acta, 1996, 242, 281.

26 S. J. Coles and P. A. Gale, Chem. Sci., 2012, 3, 683.

27 G. M. Sheldrick, Acta Crystallogr., Sect. A: Found. Adv., 2015, $71,3$.

28 O. V. Dolomanov, L. J. Bourhis, R. J. Gildea, J. A. K. Howard and H. Puschmann, J. Appl. Crystallogr., 2009, 42, 339.

29 G. M. Sheldrick, Acta Crystallogr., Sect. C: Struct. Chem., 2015, $27,3$.

30 M. J. Frisch, G. W. Trucks, H. B. Schlegel, G. E. Scuseria, M. A. Robb, J. R. Cheeseman, G. Scalmani, V. Barone, B. Mennucci, G. A. Petersson, H. Nakatsuji, M. Caricato, X. Li, H. P. Hratchian, A. F. Izmaylov, J. Bloino, G. Zheng, J. L. Sonnenberg, M. Hada, M. Ehara, K. Toyota, R. Fukuda, J. Hasegawa, M. Ishida, T. Nakajima, Y. Honda, O. Kitao, H. Nakai, T. Vreven, J. A. Montgomery Jr, J. E. Peralta, F. Ogliaro, M. Bearpark, J. J. Heyd, E. Brothers, K. N. Kudin, V. N. Staroverov, T. Keith, R. Kobayashi, J. Normand, K. Raghavachari, A. Rendell, J. C. Burant, S. S. Iyengar, J. Tomasi, M. Cossi, N. Rega, J. M. Millam, M. Klene, J. E. Knox, J. B. Cross, V. Bakken, C. Adamo, J. Jaramillo, R. Gomperts, R. E. Stratmann, O. Yazyev, A. J. Austin, R. Cammi, C. Pomelli, J. W. Ochterski, R. L. Martin, K. Morokuma, V. G. Zakrzewski, G. A. Voth, P. Salvador, J. J. Dannenberg, S. Dapprich, A. D. Daniels, O. Farkas, J. B. Foresman, J. V. Ortiz, J. Cioslowski and D. J. Fox, Gaussian 09, Revision C.01, Gaussian Inc., Wallingford CT, 2010.

31 E. F. Pettersen, T. D. Goddard, C. C. Huang, G. S. Couch, D. M. Greenblatt, E. C. Meng and T. E. Ferrin, J. Comput. Chem., 2004, 25, 1605. 